\title{
Aristolochia longa (Aristolochiaceae) Spice Alleviates Nickel-Induced Oxidative Stress and Biochemical Alterations in Rats
}

\author{
Ibtissam $\mathrm{L}^{1}$, Samir $\mathrm{D}^{1,2 *}$ and Wiam $\mathrm{Z}^{1}$ \\ ${ }^{1}$ Department of Cellular and Molecular Biology, Faculty \\ of Natural Science Sand Life, University of El Oued, El- \\ Oued, Algeria \\ ${ }^{2}$ Laboratory of Biodiversity and Application of \\ Biotechnology in the Agricultural Field, University of El \\ Oued, El-Oued, Algeria \\ *Corresponding author: Derouiche Samir, \\ Department of Cellular and Molecular Biology, Faculty \\ of Natural Science Sand Life, University of El Oued, El- \\ Oued 39000, Algeria; Laboratory of Biodiversity and \\ Application of Biotechnology in the Agricultural Field, \\ University of El Oued, El-Oued 39000, Algeria
}

Received: August 18, 2021; Accepted: September 03, 2021; Published: September 10, 2021

\begin{abstract}
The objective of this work is to study the protective effect of Aristolochia longa against the variation of biochemical parameters and oxidative stress in rats exposed sub acutely to nickel. This is an experimental study carried out in the laboratory on 15 female Wistar rats divided into three groups $(n=5)$, the first group of which serves as a control, the second group is contaminated with nickel, the third group is contaminated with nickel and treated with $A$. longa. Biochemical and oxidative stress parameters were analyzed on the rats of the various. The aqueous extract of $A$. longa included a variety of bioactive components, including polyphenols, saponins, terpenoids, glycosides, and flavonoids, according to phytochemical screening results, and nickel treatment resulted in a considerable increase in serum Urea, Uric acid, creatinine and GOT, GPT activities. The results obtained also reveal a bioaccumulation of $\mathrm{Ni}$ and an oxidative stress in group contaminated with nickel, with an increase in the level of hepatic Ni and a significant augmentation in the Kidney MDA and decrease in the level of GSH and the activity of tissue SOD. Treatment with A. longa improves biochemical parameters and reduces tissue nickel levels, with protection of organs against oxidative radical attacks induced by nickel. In conclusion, this study shows that treatment with $A$. longa induces a beneficial effect against the toxicity of nickel at the molecular and tissue level.
\end{abstract}

Keywords: Aristoloshia longa; Nickel; Liver; Kidney; Oxidative stress; Wistar rats

\section{Introduction}

Man and his surroundings have been exposed to various harmful heavy metals as a result of the rapid development of technological sciences, industries (chemical and metallic), medicine, and agriculture. Heavy metals including nickel, cadmium, lead, and others build up in the body, causing short- and long-term harmful effects [1]. They have the potential to harm the neurological system, kidneys, liver, and lungs [2]. Nickel comes in different chemical forms, but it only effectively enters cells in the bivalent cationic form $\left(\mathrm{Ni}^{2+}\right)$ or as nickel chloride or sulfate [3]. Nickel ion can cause direct damage to all cellular components: peroxidation of lipids, proteins and nucleic acids, due to free radical attacks generated by nickel [4]. Nickel ion can cause direct damage to all cellular components: peroxidation of lipids, proteins and nucleic acids, due to free radical attacks generated by nickel [5]. With these radicals or indirectly by producing peptides such as metallothioneins or glutathione [6]. Numerous studies indicate massive production of oxidant species and inhibition of the activities of major antioxidant enzymes due to the cytotoxicity of nickel in a cell can promote excessive cell death or tumor development [7]. Herbal medicine is the art of healing yourself with plants. Currently, many drugs originate from medicinal plants. Aristolochia longa $\mathrm{L}$ is a plant widely used in traditional medicine in the treatment of cancer and other chronic diseases in several regions of Algeria [8]. In the light of these data, our objective for this study is to evaluate the effectiveness of a therapeutic system based on herbal medicine by Aristolochia longa against oxidative stress and toxic effects of nickel in rats.

\section{Materials and Methods}

\section{Plant materials and preparation of aqueous extract}

Aristolochia longa roots wood was taken from a local market in El-Oued by herbalists. The vegetable materials were rinsed in water and then dried for 48 to 92 hours at room temperature. Crushed into a powder, then kept at room temperature until needed. About $10 \mathrm{~g}$ of $A$. longa root powder was soaked in $100 \mathrm{ml}$ of distilled water and stored at room temperature for 24 hours in the dark. Following that, it was filtered using filter paper. After extraction, the water was evaporated using a rotary evaporator, and the sample was then dried thoroughly at $40^{\circ} \mathrm{C}$. For future analysis, the extract was weighed and stored in a refrigerator at $4^{\circ} \mathrm{C}[9]$.

\section{Animals and handling}

Experiments and Animals Female albino rats, 8 weeks old and weighing around $190 \mathrm{~g}$, were procured from the Pasteur Institute's animal home in Algeria. The animals were given free access to a regular feed as well as distilled water. Rats were separated into three groups of 5 rats each after the adaption phase and kept in the animal house of the El-Oued University. Unless otherwise stated, standard rat food and water were supplied ad libitum during the tests. Animals were acclimated for two weeks under the identical lab conditions of photoperiod (12 hours of light/12 hours of darkness), relative 
humidity 65.3 percent, and room temperature $23 \pm 2 \mathrm{C}^{\circ}$.

\section{Experimental design}

The experimental methods were carried out in accordance with the National Institute of Health's Animal Care Guidelines and were authorized by our institution's Ethics Committee. Over the course of 20 days, the experiment was carried out. The animals were divided into three experimental groups of five animals each after a period of adaptation:

Group 1 (Control group): Animals served as normal control.

Group 2 (Ni): Rats exposed to nickel (20mg / kg rat weight) for 20 days.

Group $3(\mathrm{Ni}+\mathrm{Ar})$ : Rats exposed to nickel and treated with Aristolochia Longa powder for 20 days.

Aristolochia longa (roots powder) were added to the feed (at a dose $5 \%$ of diet).

\section{Preparation of serum and tissue samples}

Rats were fasted for 16 hours after receiving Aristolochia longa therapy, anaesthetized with chloroform by inhalation, beheaded, and blood was placed into non-heparinized tubes for serum biochemical examination. Blood was centrifuged at $3000 \mathrm{rpm}$ for 10 minutes to obtain serum, which was then rapidly frozen at $20^{\circ} \mathrm{C}$ until used. Liver and kidney samples were quickly excised, weighed, and rinsed in icecold saline ( 0.9 percent $\mathrm{NaCl}(\mathrm{w} / \mathrm{v})$ before being treated for oxidative stress marker analysis.

\section{Phytochemical screening}

In our study, the methods descripted by Zebidi et al. [10] were used to identify the different phytochemicals in extracts such as flavonoids, alkaloids, saponins, tannins, terpenoids and glycosides.

\section{Determination of total phenolic, flavonoids content and antioxidant activity}

The Folin-Ciocalteu technique was used to determine the polyphenols. Slinkard and Singleton [11] were the first to describe this strategy. Lin and Tang [12] proposed a method for determining the total flavonoid content of the aqueous extracts of Aristolochia longa. Burits and Bucar [13] proposed a method for determining in vitro antioxidant activity by evaluating the scavenging power of the DPPH (1,1-diphenyl-2-picryhydrazyl) radical.

\section{Determination of tissue Nickel concentration}

Dry calcination of liver is done for 6 hours in a muffle furnace at $600^{\circ} \mathrm{C}$. An acid attack of $3 \mathrm{ml}$ pure nitric acid dissolves the ash produced $\left(\mathrm{HNO}_{3}\right)$. In a $20 \mathrm{ml}$ flask, the liquid is filtered through filter paper and finished with demineralized water to reach its ultimate volume. Nickel standards are made from a 1000-ppm stock solution for the nickel assay.

\section{Biochemical parameters analysis}

Urea, uric acid, creatinine, serum protein in serum were determined using the commercial kit from Spinreact, Spain (ref: urea20141, uric acid-20091, creatinine-20151, total protein-1001291). And for enzymes TGO and TGP are also measured by the use of commercial kits (Spinreat, ref: GOT-20042, GPT-20046).

\section{Measurement of oxidative stress markers}

Liver Malondialdehyde (MDA) and kidney was measured according to the method described by Yagi et al. [14]. The concentration of reduced Glutathione (GSH) was performed with the method described by Weckbecker, [15] and superoxide was measured by the method of Beauchamp [16].

\section{Statistics analysis}

Mean data values are presented, with their standard deviations (mean $\pm \mathrm{SD}$ ). The Student's t-test was used to do all statistical comparisons, and statistical significance was determined as $\mathrm{P}<0.05$.

\section{Results}

\section{Results of phytochemical analysis}

Results showed the existence of alkaloids, glycosides, phenol compounds, tannins, flavonoids, Terpenoids and saponins in the extract plants (Table 1). These compounds are antioxidant activities, which could play a major role in the capture of free radicals induced by heavy metal such as nickel.

\section{Quantification of phytochemical compounds}

Total phenolic and flavonoid compounds were expressed in terms of Gallic acid equivalent (mg GA eq/g dry extract) and of Quercetin equivalent ( $\mathrm{mg} \mathrm{Q}$ eq/g dry extract) respectively, using the following equations based on the calibration curve: $\mathrm{Y}=0.0045 \mathrm{x}+0.09, \mathrm{R} 2=$ 0.9925 for phenolic compounds and $\mathrm{Y}=0.0096 \mathrm{x}+0.0521, \mathrm{R} 2=0.994$ for flavonoids compounds (Table 2).

\section{Antioxidant (DPPH) test}

Table 3 presented the results of the antioxidant power of the extracts tested show that the percentage inhibition of the aqueous extract of A. longa at a concentration of $12.23 \mathrm{mg} / \mathrm{ml}$, which is calculated by the equation $\mathrm{y}=1.6181 \mathrm{x}+30.757$ with $\mathrm{R} 2=0.9882$, obtained by a curve of percentage inhibition as a function of the concentrations of the extract of A. longa. Likewise, the percentage inhibition of ascorbic Table 1: Phytochemical composition of aqueous extracts of rhizome Aristolochia longa.

\begin{tabular}{|c|c|}
\hline Phytochemical & A. longa \\
\hline Total phenols & + \\
\hline Flavonoids & + \\
\hline Tannins & + \\
\hline Alcaloids & + \\
\hline Saponines & + \\
\hline Terpenoids & + \\
\hline Glycosids & + \\
\hline
\end{tabular}

+Presence of phytochemicals.

Table 2: Phenolic and flavonoids content from $A$. longa aqueous extract.

\begin{tabular}{|l|c|}
\hline \multicolumn{1}{|c|}{ Phytochemical } & A. longa \\
\hline Total phenolics (mg GA eq/g dry extract) & $9.20 \pm 0.05$ \\
\hline Total flavonoids (mg Q eq/g dry extract) & $2.17 \pm 0.04$ \\
\hline
\end{tabular}

Table 3: $\mathrm{IC}_{50}$ value of aqueous extract of $A$. longa and ascorbic acid.

\begin{tabular}{|l|c|}
\hline \multicolumn{1}{|c|}{ Sample } & IC $_{50}(\mu \mathrm{g} / \mathrm{ml})$ \\
\hline Aristoloshia longa & $12.23 \pm 0,42$ \\
\hline Ascorbic acid & $2.89 \pm 0,09$ \\
\hline
\end{tabular}


Table 4: Mean initial Body weight, Weight gains relative liver weight of control and experimental rats $(n=5)$.

\begin{tabular}{|l|c|c|c|}
\hline \multicolumn{1}{|c|}{ Parameter } & Control & Nickel & Nickel + Ar \\
\hline Initial Body Weight $(\mathrm{g})$ & $194.80 \pm 6.26$ & $167.80 \pm 16.4$ & $185.60 \pm 8.01$ \\
\hline Weight Gains (g/d/rat) & $0.05 \pm 0.08$ & $-1.03 \pm 0.30^{*}$ & $-0.16 \pm 0.01^{\text {*a }}$ \\
\hline Relative Liver Weight & $2.92 \pm 0.16$ & $2.56 \pm 0.26^{* *}$ & $2.68 \pm 0.19^{\text {Ns }}$ \\
\hline Relative Kidney Weight & $0.58 \pm 0.01$ & $0.70 \pm 0.05^{*}$ & $0.40 \pm 0.02^{\mathrm{b}}$ \\
\hline
\end{tabular}

Values are mean $\pm \mathrm{SEM}$; $\mathrm{n}$ : number of observations. ${ }^{*} \mathrm{p}<0.05,{ }^{* *} \mathrm{p}<0.01$ Significantly different from control group; ${ }^{a} p<0.05$, ${ }^{b} p<0.01$ : Significantly different from Ni group

Table 5: Biochemical markers Levels in control and experimental group $(n=5)$.

\begin{tabular}{|l|c|c|c|}
\hline \multicolumn{1}{|c|}{ Parameter } & Control & Nickel & Nickel + Ar \\
\hline Liver Ni $(\mu \mathrm{g} / \mathrm{g})$ & $6.98 \pm 0.54$ & $10.35 \pm 1.59^{*}$ & $7.26 \pm 1.29^{\mathrm{NSb}}$ \\
\hline Serum Urea $(\mathrm{g} / \mathrm{l})$ & $0.48 \pm 0.05$ & $0.67 \pm 0.17^{* *}$ & $0.55 \pm 0.17^{\mathrm{c}}$ \\
\hline Serum Creatinine $(\mathrm{mg} / \mathrm{l})$ & $7.42 \pm 0.91$ & $7.91 \pm 0.69^{*}$ & $7.85 \pm 0.81^{\mathrm{NS}}$ \\
\hline Serum Uric Acid $(\mathrm{mg} / \mathrm{l})$ & $18.07 \pm 1.09$ & $29.73 \pm 0.99^{*}$ & $15.55 \pm 0.34^{\mathrm{c}}$ \\
\hline Serum Total Proteins $(\mathrm{g} / \mathrm{l})$ & $62.23 \pm 0.56$ & $71.46 \pm 0.88^{* * *}$ & $82.34 \pm 0.76^{* * * \mathrm{a}}$ \\
\hline Serum GOT $(\mathrm{U} / \mathrm{l})$ & $93.00 \pm 23.10$ & $185.20 \pm 14.30^{* * *}$ & $130.86 \pm 1.54^{* *+\mathrm{C}}$ \\
\hline Serum GPT $(\mathrm{U} / \mathrm{l})$ & $38.61 \pm 8.13$ & $54.07 \pm 6.63^{* *}$ & $36.09 \pm 2.74^{\mathrm{c}}$ \\
\hline
\end{tabular}

Values are mean \pm SEM; $n$ : number of observations. ${ }^{*} p<0.05,{ }^{* *} p<0.01$, ${ }^{* *} p$ $<0.001$ : Significantly different from control group; ${ }^{a} p<0.05,{ }^{b} p<0.01$ : Significantly different from Ni group.

acid at $2.89 \mathrm{mg} / \mathrm{ml}$, which is calculated by the equation $\mathrm{y}=0,0.6232 \mathrm{x}+$ 48.111 with $\mathrm{R} 2=0.9607$, obtained by a percentage curve $\mathrm{d}$ 'inhibition as a function of ascorbic acid concentrations.

\section{Initial body weight, body weight gain and relative liver weight}

In comparison to the control rats, nickel treatment at a dose of $20 \mathrm{mg} / \mathrm{kg}$ body weight induce a decrease $(\mathrm{p}<0.05)$ in body weight and an increase $(\mathrm{p}<0.05)$ in Relative Kidney weight. The animals who were given rhizome A. longa powder demonstrated a partial reversal of this alteration (Table 4).

\section{Hepatic nickel and Biochemical parameters levels}

The content of nickel in the liver of nickel-contaminated rats increased significantly ( $\mathrm{p}<0.05)$, as shown in Table 5 of our findings. The treatment of $A$. longa powder to nickel-exposed rats, on the other hand, considerably reduced the levels of lead in the liver $(\mathrm{p}<0.01)$. Our findings reveal a significant increase $(\mathrm{p}<0.001)$ in urea, uric acid and total protein $(\mathrm{p}<0.001)$ in the nickel-contaminated group when compared to controls. Our findings in Table 5 show a very significant $(\mathrm{p}<0.001)$ and extremely significant $(\mathrm{p}<0.01)$ increase in transaminase (TGO, TGP) activity in the nickel-contaminated group when compared to controls. On the other hand, we found a significant reduction in urea levels in the $A$. longa treatment groups $(\mathrm{p}<0.01$ and $\mathrm{p}<0.05)$ and serum uric acid content $(\mathrm{p}<0.001)$, as well as a very substantial drop in TGO $(\mathrm{p}<0.001)$ and TGP. However, no difference in serum creatinine has been seen as compared to the Nickel group.

\section{Oxidative stress parameters levels}

Table 6 shows that rats in the nickel group had a substantial rise $(\mathrm{p}<0.05)$ in lipid peroxidation in the kidney and a significant decrease $(\mathrm{p}<0.05)$ in GSH concentration and SOD activity in the liver and kidney when compared to the control group. In contrast, our findings demonstrate that MDA levels in the kidney are significantly lower $(\mathrm{P}$
Table 6: Oxidative stress markers levels of control and experimental groups $(n=5)$

\begin{tabular}{|l|c|c|c|c|}
\hline \multicolumn{2}{|c|}{ Parameter } & Control & Nickel & Nickel + Ar \\
\hline \multirow{2}{*}{ MDA ( $\mu \mathrm{mol} / \mathrm{mg}$ pro) } & Liver & $2.54 \pm 0.04$ & $2.38 \pm 0.33^{\mathrm{Ns}}$ & $1.58 \pm 0.27^{* * \mathrm{a}}$ \\
\cline { 2 - 5 } & Kidney & $1.79 \pm 0.03$ & $2.19 \pm 0.14^{*}$ & $1.797 \pm 0.01^{\mathrm{b}}$ \\
\hline \multirow{2}{*}{ GSH (nmol/mg pro) } & Liver & $1.19 \pm 0.27$ & $0.77 \pm 0.23^{*}$ & $1.52 \pm 0.15^{*}$ \\
\cline { 2 - 5 } & Kidney & $0.10 \pm 0.01$ & $0.04 \pm 0.01^{* * *}$ & $0.08 \pm 0.01^{* *}$ \\
\hline \multirow{2}{*}{ SOD (Ul/mg pro) } & Liver & $7.25 \pm 0.13$ & $3.13 \pm 0.64^{*}$ & $4.52 \pm 1.61^{*}$ \\
\cline { 2 - 5 } & Kidney & $0.22 \pm 0.01$ & $0.17 \pm 0.02^{* *}$ & $0.23 \pm 0.02^{* \mathrm{c}}$ \\
\hline
\end{tabular}

Values are mean \pm SEM; $n$ : number of observations. ${ }^{*} p<0.05,{ }^{* *} p<0.01,{ }^{* * *} p$ $<0.001$ : Significantly different from control group; ${ }^{a} p<0.05,{ }^{b} p<0.01$ : Significantly different from $\mathrm{Ni}$ group

$<0.01$ ), whereas GSH concentration and SOD activity in the kidney and liver are significantly higher in A. longua groups compared to Ni groups.

\section{Discussion}

In search of new biologically active compounds, new herbal agents could be used to enhance the antioxidant of standard drug therapy. For this study, we are evaluating the effects of Aristoloshia longa against disturbance and damage induced by nickel. Regarding the DPPH antioxidant test, according to the recorded results, the aqueous extracts of A. longa have moderate antioxidant power. The polyphenols contained in the extract of this plant are probably responsible for the antioxidant activity and have anti-radical activities of these extracts [17]. The reduction in body weight is used as an indicator of the deterioration of the general health of the rat. This effect can also be explained by the action of pollutants on the transport of nutrients (amino acids, glucose and essential minerals such as zinc, magnesium, iron) by the blood and consequently, they can induce a poor assimilation of food by the body [18]. Regarding the relative weights of the organs, we notice a hypotrophy hepatic; this is explained by the intense accumulation of this metal in these target organs [19]. This increase in relative organ weight may be due to nickel-induced necrosis [20]. Treatment by aqueous extract of $A$. longa has shown improvement in relative organ weight. This result is in agreement with the study by Derouiche et al. [21]. A. longa is probably due to the three phytochemicals identified in this plant as flavonoids (folavonol, flavones and/or flavonoids glycosides) exerting a nickel chelating effect which decreases their toxic effect on these organs and therefore decreases the relative weight. The concentration of nickel in liver tissue increased following administration of nickel to normal rats. Because the liver is the main target of environmental and occupational toxicity and the main site of detoxification [22]. Nickel enters all organs and accumulates mainly in the liver [23]. They can cause certain morphological transformations in many cellular systems [24]. On the other hand, administration of $A$. longa reduced the level of nickel in liver tissue in favor of a detoxification process. Due to their specific chemical structure, flavonoids can chelate metal ions and form complexes [25]. Causes a regulatory action on hepatic functions. Our study of renal function showed increased serum urea, creatinine and uric acid levels in rats treated with nickel. The high serum urea concentration can be explained by the catabolism of protein compounds in the body under the action of glucocorticoid hormones, which play an important role in this process, where proteins can be broken down into amino acids and then urea. Nickel 
accumulates in the kidneys, where it induces lesions in the glomeruli and proteinuria, which testifies to the onset of transient renal failure, with reduced glomerular filtration [26]. Nickel poisoning caused a significant increase in the activities of TGP, TGO. The liver constitutes an important target for nickel, which leads to hepatic necrosis and the release of aminotransferases (TGO and TGP) which clearly explains the hepatotoxic effect of nickel, which is, entered cells and crossed the nuclear membrane [27]. The usage of rats by A. longa dramatically recovered enzymatic activity and renal biomarkers in serum or tissues compared to nickel-exposed rats, implying that these plants reduce hepatic damage caused by nickel. This is related to Aristolochia's ability to reduce the formation of free radicals and protect against oxidative stress. Aristolochia species' anti-inflammatory properties are most likely due to a direct interaction between aristolochic acid and phospholipid A2 derivatives [28]. The major component of Aristolochia longa is aristolochic acid. Furthermore, phospholipase A2 is an enzyme that catalyzes the hydrolysis of arachidonic acid in the membrane, resulting in the generation of local inflammatory mediators Prostaglandins (PG), leukotrienes, and thromboxanes are examples. Arachidonic acid is a critical biological intermediary that is transformed into a variety of biologically active eicosanoids [29]. In our study, nickel poisoning induce oxidative stress by increasing lipid peroxidation and decreasing levels of antioxidant defense systems GSH and SOD in the liver and Kidney the results show a significant decrease in hepatic and kidney glutathione level in rats contaminated with nickel. This explained by the harmful effects of the action of nickel in the body and the induction of the formation of Reactive Oxygen Species (ROS) and the increase in lipid peroxidation in cells. radical oxidation process in which polyunsaturated fatty acids in the cell membrane [18] break down to give, among others, highly reactive lipid hydroperoxides $\left(\mathrm{H}_{2} \mathrm{O}_{2}\right)$, a hydroxyl radical $\left(\mathrm{OH}^{\circ}\right)$ and malondialdehyde can inactivate the enzyme [30]. Reduced SOD activity in the present study can lead to the generation of a peroxy radical, $\mathrm{O}_{2}$, associated with the inactivation of SOD. The remarkable improvement in oxidative stress parameters after treatment with $A$. Longa this fact by the phenolic groups of polyphenols can accept an electron to form the phenoxyl radicals relatively stable, which disrupt the chain oxidation reactions of cellular components [31]. Phenolic compounds (in particular flavonoids) are able to modify the kinetics of peroxidation by modifying the order of lipid filling [32]. These phenolic compounds express the antioxidant properties by; direct trapping of reactive oxygen species, suppression of ROS formation by inhibiting some enzymes or chelating metal ions involved in their production [33].

\section{Conclusion}

This study's findings imply that $A$. longa rhizome powder therapy reduces nickel-induced liver damage and nickel buildup. A. longa could be a truly functional food that helps to promote health by lowering nickel toxicity thanks to its antioxidant properties.

\section{Acknowledgement}

This work was supported by the research project D01N01UN390120190001 funded by the ministry of higher education, Algeria and by Directorate general for Scientific Research and Technological Development.

\section{References}

1. Derouiche S, Cheradid T, Guessoum M. Heavy metals, Oxidative stress and Inflammation in Pathophysiology of Chronic Kidney disease - A Review. Asian J of Pharmacy and Technology. 2020; 10: 202-206.

2. Das KK, Dasgupta S. Effect of nickel sulfate on testicular steroidogenesis in rats during protein restriction. Environ. Health Perspect. 110: 923-926.

3. Harber LT, Diamond GL, Zhao Q, Erdreich L, Dourson ML. Hazard identification and dose response of ingested nickel-soluble salts. Regul. Toxicol. Pharmacol. 31: 231-241.

4. Sunderman FW, Marzouk JR, Hopfer SM, Zaharia O, Reid MC. Increased lipid peroxidation in tissues of nickel chloride-treated rats. Ann Clin Lab Sci. 1985; 15: 229-223.

5. Phaniendra A, Jestadi DB, Periyasamy L. Free radicals: properties, sources, targets, and their implication in various diseases. Indian J Clin Biochem. 2015; 30: 11-26.

6. Lou J, Jin L, Wu N, Tan Y, Song Y, Gao M, et al. DNA damage and oxidative stress in human $\mathrm{B}$ lymphoblastoid cells after combined exposure to hexavalent chromium and nickel compounds. Food Chem Toxicol. 55: 533-540.

7. Hattiwale SH, Saha S, Yendigeri SM, Jargar JC, Dhundasi SA, Das KK. Protective effect of L-ascorbic acid on nickel induced pulmonary nitrosative stress in male albino rats. Biometals. 2013; 26: 329-336.

8. Derouiche S, Kaouther A, Manal D. Polysaccharides and ascorbic acid content and the effect of aqueous extract of Portulaca oleracea in high-fat diet-induced obesity, dyslipidemia and liver damage in albino wistar rats. Algerian $\mathrm{J}$ arid environ. 2017; 7: 16-26.

9. Benzakour G, Amrani M, Oudghiri MA. A Histopathological analyses of in vivo anti-tumor effect of an aqueous extract of Aristolochia longa used in cancer treatment in traditional medicine in Morocco. Int J Plant Res. 2012; 2: 31-35.

10. Zebidi M, Seghiri I, Mehellou Z, Derouiche S. Evaluation of Antioxidant and Antidiabetic activity of leave aqueous extracts of Oudneya Africana. World J Pharm Sci. 2018; 6: 48-53.

11. Slinkard K, Singleton VL. Total Phenol Analysis: Automation and Comparison with Manual Methods. Am J Enol Viticult. 1977; 28: 49-55.

12. Ahn M, Kumazawa S, Usui Y, Nakamura J, Matsuka M, Zhu F, et al. Antioxidant activity and constituents of propolis collected in various areas of China. Food Chem. 101: 1383-1392.

13. Mansouri A, Embarek G, Kokkalou E, Kefalas P. Phenolic profile and antioxidant activity of the Algerian ripe date palm fruit (Phoenix dactylifera). Food Chem. 2004; 89: 411-420.

14. Yagi K. A simple fluorometric assay for lipoperoxide in blood plasma. Biochem Med. 15: 212-216.

15. Weckbecker G, Cory GH. Ribonucleotide reductase activity and growth of glutathione-depleted mouse leukemia L1210 cells in vitro. Cancer Letters. 1988; 40: 257-264

16. Beauchamp C, Fridovich I. Superoxide dismutase: Improved assays and an assay applicable to acrylamide gels. Anal Biochem. 1971; 44: 276-287.

17. Derouiche S, Cheradid Taissir, Abdelmolk Djoumana, Achi Ikram. Effect of COVID-19 Infection on the Immune System and Risk of Developing Diabetes Complications: A Review. J Pharm Care. 2020; 8: 133-139.

18. Pardeep S, Garg ML, Dhawan DK. Effect of Zinc on Biological Half-Lives of $65 \mathrm{Zn}$ in Whole Body and Liver and on Distribution of 65Zn in Different Organs of Rats Following Nickel Toxicity. Biol Trace Elem Res. 2004; 102: 173-188.

19. Sani A, Abdullahi IL, Ibrahim S. Histopathological changes associated with exposure to metal welding fumes in some organs of Rattus norvegicus in Kano, Nigeria. Toxicol Rep. 2021; 8: 422-428.

20. Ahn M, Kumazawa S, Usui Y, Nakamura J, Matsuka M, Zhu F, et al. Antioxidant activity and constituents of propolis collected in various areas of China. Food Chem. 101: 1383-1392.

21. Derouiche S, Zeghib K, Gharbi S, Khelef Y. Beneficial Effects of Aristolochia longa and Aquilaria malaccensis on Lead-Induced Hematological Alterations 
and Heart Oxidative Stress in Rats. J Chem Pharm Res. 2018; 10: 8-15.

22. Das K, Das K, Gupta SD. Influence of ascorbic acid against nickel-induced hepatic lipid peroxidation in rats. J Basic Clin Phys Pharm. 2001; 12: 187-195.

23. Das KK, Das SN. Studies on the role of ascorbic acid in nickel induced hepatic nucleic acid concentrations in rats. J Basic Clin Phys Pharm. 2004 15: $185-195$.

24. Coen N, Mothersill C, Kadhim M, Wright EG. Heavy metals of relevance to human health induce genomic instability. J Pathology. 2001; 195: 293-299.

25. Keilig K, Ludwig-Müller J. Effect of flavonoids on heavy metal tolerance in Arabidopsis thaliana seedlings. Botanical Studies. 2009; 50: 311-318.

26. Tikare S, Yendigeri S, Das GA, Salim AD, Das KK. Protective effect of a tocopherol against hematotoxicity, hepatotoxicity and nephrotoxicity induced by nickel sulfate in male albino rats. Indian J. Physiol. Pharmacol. 2016; 57: 280-292.

27. Patierno SR, Sugiyama M, Costa M. Effect of nickel (II) on DNA-protein binding, thymidine incorporation, and sedimentation pattern of chromatin fractions from intact mammalian cells. J Biochem Toxicol. 2001; 2: 13-23.

28. Derouiche S, Khaoula Z. Evaluation of the Chelating Efficacy of Aquilaria malaccensis and Aristolochia longa Against Biochemical Alterations Induced by Lead Bioaccumulation in Rats. Pharm Biosci. J. 2019; 7: 11-15

29. Houghton P. Anti-inflammatory plants ethnopharmacology of medicinal plants: Asia and the pacific. Br J Clin Pharmacol. 2007; 64: 248.

30. Derouiche S, Kechrid Z. Influence of calcium supplements on zinc status, carbohydrate metabolism and the liver activity of detoxifying glutathione enzymatic system in alloxan induced diabetic rats. J Exp Biol Agr Sci. 2013; 1: $424-429$.

31. Grassmann J. Terpenoids as plant antioxydant. Vit hormon. 2005; 72: 505 535.

32. Derouiche S, Degachi O, Gharbi K. Phytochemistry analysis and modulatory activity of Portulacae oleracea and Aquilaria malaccensis extracts against High-fructose and high-fat diet induced immune cells alteration and heart lipid peroxidation in Rats. Int Res J Bio Sci. 2019; 8: 6-11.

33. Nik N, Will A, Nor A, Mhd O, Awang N, Tajuddin SN. In vitro antioxidant activity and phytochemical screening of Aquilaria malaccensis leaf extraits. J Chem Pham Res. 2014; 6: 688-693. 